\title{
The promotion of $\mathrm{Cu}-\mathrm{SSZ}-13$ on urea decomposition
}

\section{Support Information}

\author{
Zixun Liu, ${ }^{\dagger}$ Dongwei Yao, ${ }^{\dagger},{ }^{*}$ Feng $\mathrm{Wu}^{\dagger}$
}

+ College of Energy Engineering, Zhejiang University, Hangzhou 310027, China

*Corresponding Author E-mail: dwyao@zju.edu.cn

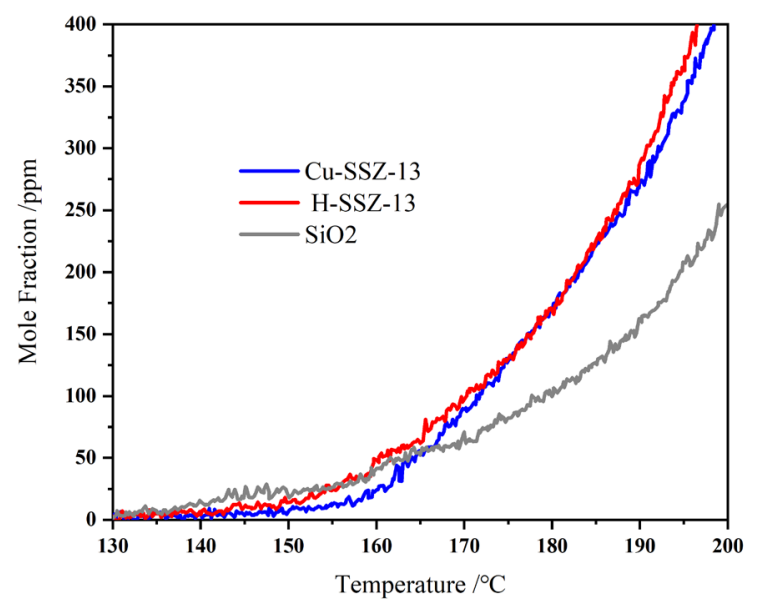

Figure S1. HNCO outcome over different catalyst without lid (reaction conditions: case 1 )

Figure S1 and S2 show the HNCO outcome over different catalyst in varies conditions. When the sample was load in an open crucible, as shown in Figure S1, HNCO was detected earlier on the silica while Cu-SSZ-13 and H-SSZ-13 were slightly later. The sample in Figure S2 was put in a crucible with a lid, which had a $1 \mathrm{~mm}$ diameter hole in the center to equalize the air pressure. The HNCO detection 


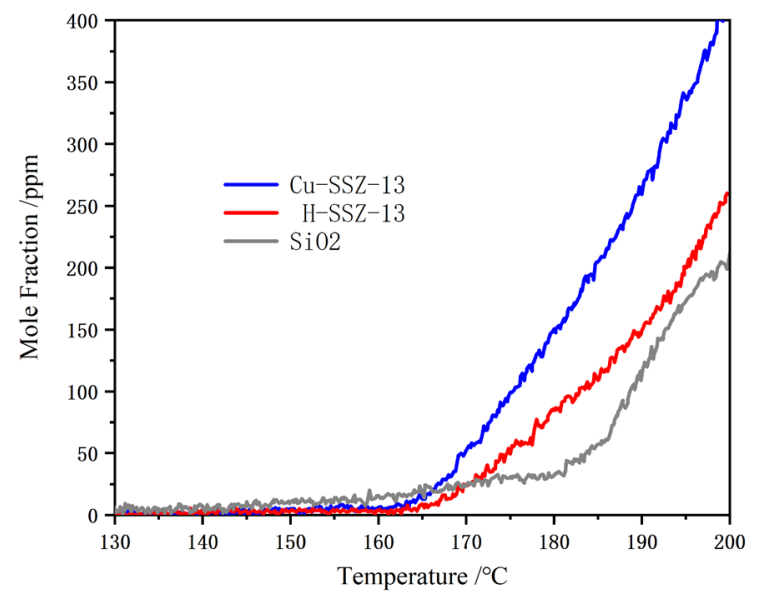

Figure S3. HNCO outcome over different catalyst with lid (reaction conditions: case 2)

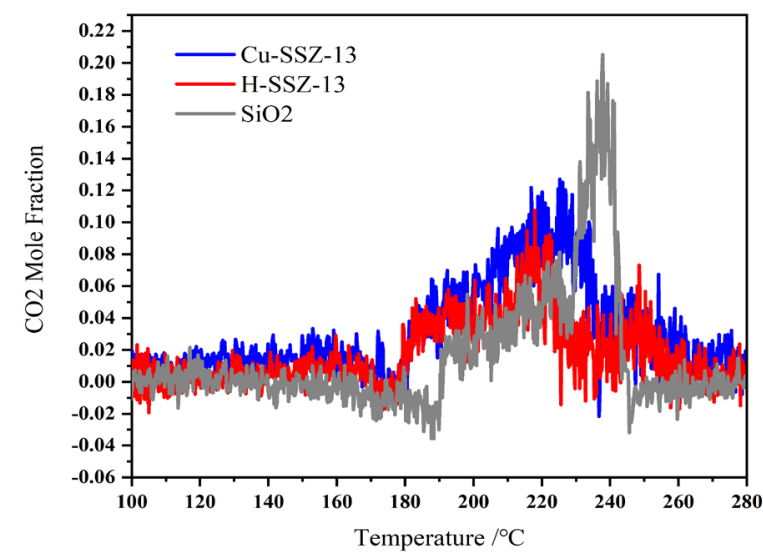

Figure S2. $\mathrm{CO}_{2}$ outcome over different catalyst (reaction conditions: case 1)

temperature is significantly delayed, but it can be seen that $\mathrm{HNCO}$ on $\mathrm{SiO}_{2}$ was still detected first. There are three possible reasons for the delayed detection of HNCO on the catalyst: A) HNCO may be catalytically hydrolyzed due to the presence of residual water in the system; B) HNCO may be consumed in the presence of the catalyst, generating other by-products; and C) HNCO may be adsorbed on the catalyst surface in the form of anions. The $\mathrm{CO}_{2}$ emissions during the TPR process (without lid) are given in Figure S3. If there is an HNCO-catalyzed hydrolysis reaction, it is logical that there should be a corresponding $\mathrm{CO}_{2}$ production. As can be seen from the figure, $\mathrm{CO}_{2}$ 
is mainly produced after $170^{\circ} \mathrm{C}$, while the $\mathrm{HNCO}$ detection delay occurs before that. Therefore reason A is not valid. Secondly, it has been shown in the main text that the final $\mathrm{NH}_{3}$ conversion exceeds $50 \%$ even in the absence of water when a catalyst is present. Moreover, the $\mathrm{NH}_{3}$ conversion curve is also consistently higher than that of $\mathrm{SiO}_{2}$, so reason $\mathrm{B}$ is also not valid, i.e., it cannot be assumed that $\mathrm{HNCO}$ was heavily involved in the side reaction when it was freshly generated. Up to this point, it can be argued that reason $\mathrm{C}$ best explains the delayed detection phenomenon of $\mathrm{HNCO}$ on the catalyst.

The CYA decomposition test on Cu-SSZ-13 was illustrated as Figure S4. Firstly

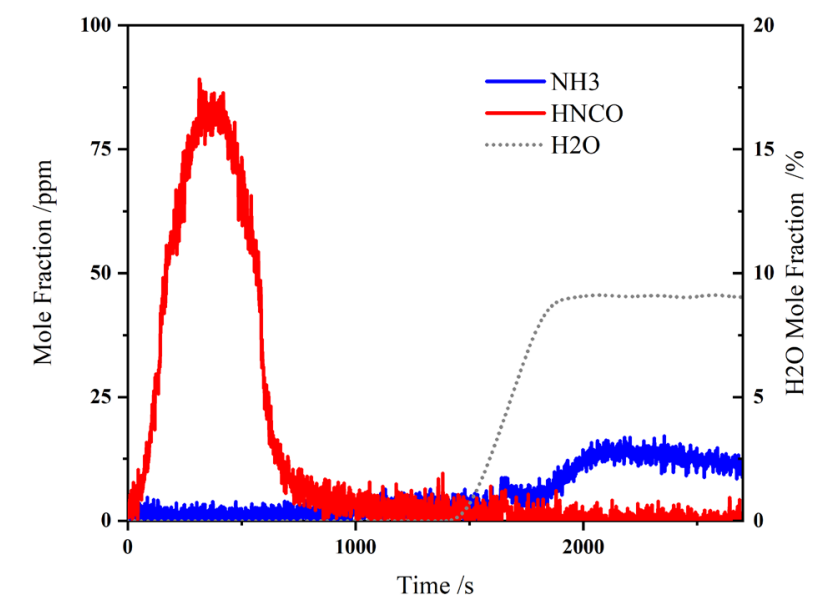

Figure S4. CYA decomposition on $\mathrm{Cu}-\mathrm{SSZ}-13$ under $360^{\circ} \mathrm{C}$ (reaction conditions: case 3 )

the pure $\mathrm{N}_{2}$ was introduced into the furnace, and then water was added in when the HNCO curve went down to zero. The HNCO outcome is much less than that on H-SSZ13, though the mass of CYA and catalysts was equal in both tests. That can be attributed to the more $\mathrm{Al}$ element in $\mathrm{H}-\mathrm{SSZ}-13$. With the same total mass and the same $\mathrm{Si} / \mathrm{Al}$ ratio, the amount of $\mathrm{Al}$ is less compared to $\mathrm{H}-\mathrm{SSZ}-13$ because $\mathrm{Cu}-\mathrm{SSZ}-13$ contains $2.9 \% \mathrm{wt}$ copper. Accordingly the $\mathrm{NH}_{3}$ outcome in Cu-SSZ-13 is less than that in H-SSZ-13. 
When CYA reaches the decomposition temperature, it will not only decompose to form

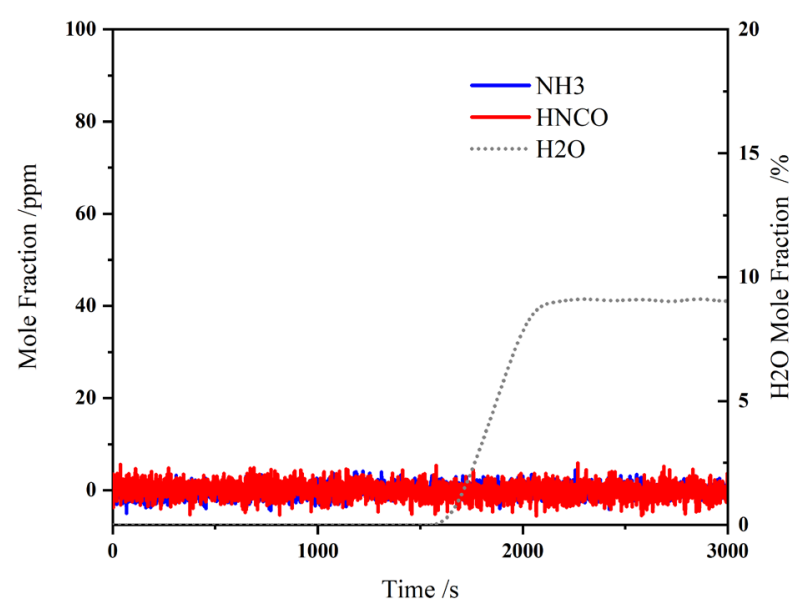

Figure S5. CYA decomposition on $\mathrm{SiO}_{2}$ under $360^{\circ} \mathrm{C}$ (reaction conditions: case 3 )

HNCO, but also sublimate itself directly. And in the absence of catalyst, CYA will trend to sublimate rather than decompose. So as shown in Figure S5, neither $\mathrm{HNCO}$ nor $\mathrm{NH}_{3}$ was detected in the tests on $\mathrm{SiO}_{2}$. It can be confirmed that the order of activity for catalytically decomposing CYA is : $\mathrm{H}-\mathrm{SSZ}-13>\mathrm{Cu}-\mathrm{SSZ}-13>\mathrm{SiO}_{2}$.

Figure S6 shows the in-situ DRIFTS spectral images of urea thermolysis over $\mathrm{TiO}_{2}$. As the in-situ reactor used in the experiment needs a layer of silica under the sample, a
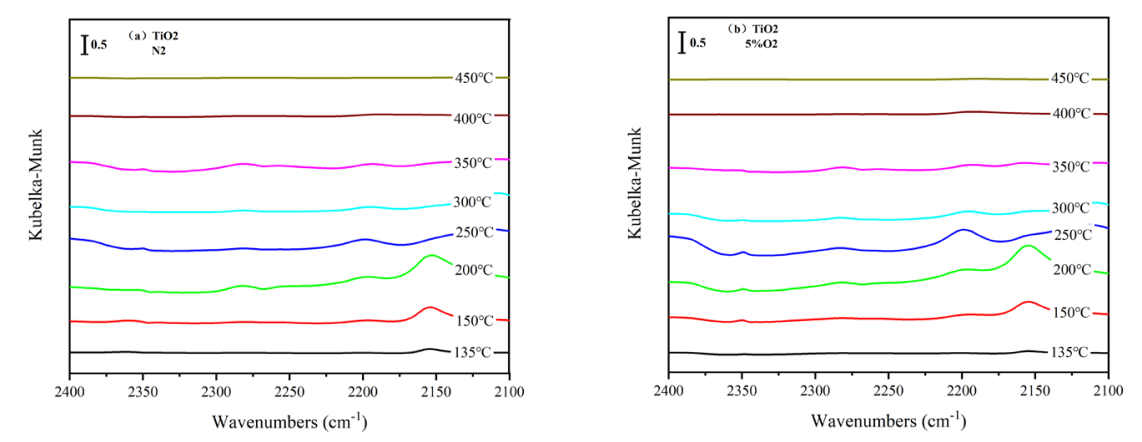

Figure S6. urea thermolysis over $\mathrm{TiO}_{2}$ (reaction conditions: a $100 \mathrm{ml} / \mathrm{min}$ (under standard condition) $\mathrm{N}_{2}$ without $\mathrm{O}_{2}$, b $95 \mathrm{ml} / \mathrm{min} \mathrm{N} 2$ with $5 \mathrm{ml} / \mathrm{min} \mathrm{O} 2$ (all under standard condition) )

group of control experiments are essential to eliminate the environmental impact. It can be seen that there is no peak at $2294 \mathrm{~cm}-1$ position in Figure S6. Hence the conclusion 
can be made that the $2294 \mathrm{~cm}-1$ peak on Cu-SSZ-13 and H-SSZ-13 is produced by SiNCO on the CHA structure of SSZ-13 rather than the silica under the samples.

Figure S7 illustrates the thermolysis and hydrolysis of biuret, the important intermediate product on $\mathrm{Cu}-\mathrm{SSZ}-13$ and $\mathrm{H}-\mathrm{SSZ}-13$. The decomposition of biuret generally begins at $190^{\circ} \mathrm{C}^{1}$, with $\mathrm{HNCO}$ and urea as the main decomposition products. However, at higher temperatures, the pyrolysis of the biuret is further combined with $\mathrm{HNCO}$ or urea to form higher molecular weight substances. Also, a viscous, solid form of biuret that polymerizes in the molten state $\left(215^{\circ} \mathrm{C}-220^{\circ} \mathrm{C}\right)$ and is referred to as biuretmatrix ${ }^{1}$. The biuret-matrix can be decomposed directly to form $\mathrm{NH}_{3}$ and $\mathrm{HNCO}$, so the $\mathrm{NH}_{3}$ and $\mathrm{HNCO}$ curves in Fig S7 may be composed from melted biuret before $220^{\circ} \mathrm{C}$, then the reaction (1) occurred to produce more $\mathrm{NH}_{3}$ and $\mathrm{HNCO}$, that cause a $\mathrm{NH}_{3}$ shoulder curve at around $250^{\circ} \mathrm{C}$. Under anhydrous conditions, the molar ratio of $\mathrm{HNCO}$ to $\mathrm{NH}_{3}$ should be close to $2: 1$, but anhydrous pyrolysis results in by-products that consume some of the HNCO, so the actual HNCO obtained is only slightly higher than $\mathrm{NH}_{3}$. in the presence of water, due to the catalytic action of the catalyst, most of the $\mathrm{HNCO}$ is hydrolyzed to produce $\mathrm{NH}_{3}$. However, unlike urea, which can be directly
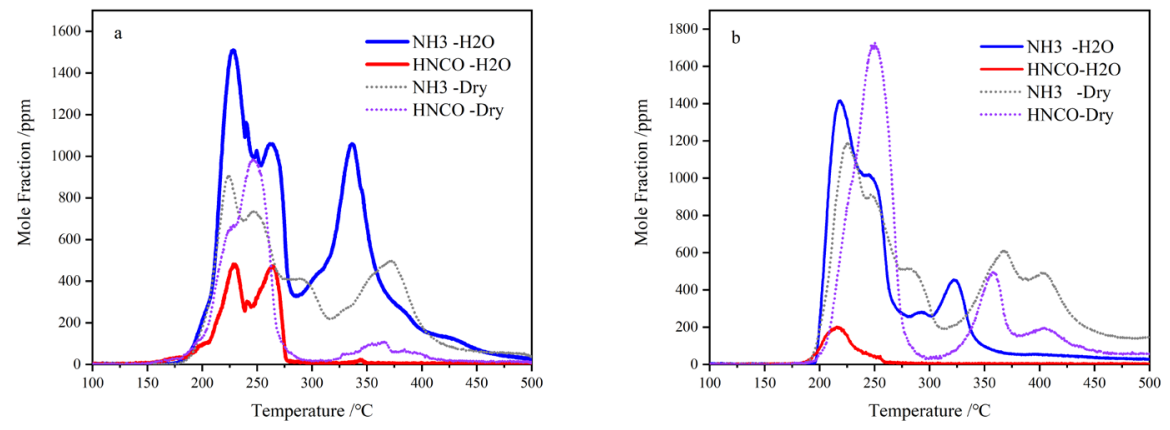

Figure S7. Biuret thermolysis and hydrolysis on different catalyst

a) $\mathrm{Cu}-\mathrm{SSZ}-13$ b) $\mathrm{H}-\mathrm{SSZ}-13$

(reaction conditions: case 4 ) 
catalyzed, biuret hydrolysis produce much more HNCO. The excess $\mathrm{HNCO}$ can react with biuret to form CYA, which would be hydrolyzed to $\mathrm{NH}_{3}$ at 300 to 400 degrees Celsius, so $\mathrm{NH}_{3}$ production in this temperature range is increased compared to urea hydrolysis.

$$
\mathrm{NH}_{2}-\mathrm{CO}-\mathrm{NH}-\mathrm{CO}-\mathrm{NH}_{2} \stackrel{\text { heated }}{\longrightarrow} 2 \mathrm{HNCO}_{(\mathrm{g})}+\mathrm{NH}_{3(\mathrm{~g})}
$$

\section{REFERENCES}

1. Brack, W.; Heine, B.; Birkhold, F.; Kruse, M.; Schoch, G.; Tischer, S.; Deutschmann, O., Kinetic modeling of urea decomposition based on systematic thermogravimetric analyses of urea and its most important by-products. Chem. Eng. Sci. 2014, 106, 1-8. 